\title{
Scanning electron microscopy and antibiotic sensitivity of the actinobacterium, Kocuria sediminis DDK6
}

\author{
Ashraf Y. Z. Khalifa ${ }^{1,2^{*}}$ \\ ${ }^{1,}$ Biological Science Department, Faculty of Sciences, King Faisal University, Saudi Arabia. \\ ${ }^{2}$ Botany and Microbiology Department, Faculty of Sciences, Beni-Suef University, Beni-Suef 65211, Egypt.
}

\section{ARTICLE INFO}

Article history:

Received on: 26/02/2017

Accepted on: 15/04/2017

Available online: 19/06/2017

Key words:

Kocuria, antibiotic sensitivity,

cell arrangements.

\begin{abstract}
In the present work, the cellular arrangements and shape of Kocuria sediminis DDK6 which was isolated from a diesel-oil contaminated soil, were investigated using scanning electron microscope (SEM). Additionally, the intrinsic antibiotic resistance of theDDK6 to 10 different antibiotics was also assessed using disc diffusion antibiotic sensitivity testing. The results obtained from SEM indicated that cells of the strain DDK6 were arranged in pairs, tetrads, packets and grape-like clusters. Typical spherical-shaped cells with a diameter between $0.7-0.9$ um, were observed. The cell surface appeared relatively smooth in texture. Additionally, circumferential rings with different spatial planes were observed in cells with various arrangements, indicating different planes of divisions. Results of intrinsic antibiotic resistance revealed that DDK6 strain was sensitive to all antibiotic tested at the applied concentration, except for the nitrofurantoin (F $300 \mu \mathrm{g}$ ). The diameter of the inhibition zone ranged between $0.85-1.3 \mathrm{~cm}$ highlighting variations in susceptibility levels to the antibiotic tested. In conclusion, DDK6 could adjust the position of the cell division site to cope with the habitat in which it lives, and resistance to the nitrofurantoin could be used as a rapid identification of Kocuria spp, in addition, to many other phenotypic traits.
\end{abstract}

\section{INTRODUCTION}

Kocuria is a heterogeneous bacterial genus and widely distributed in diverse habitats [1]. Members of Kocuria are spherical-shaped cells that form colonies with different pigmentation such as red, orange, pink, yellow or cream. Kocuria comprises 20 species and is taxonomically classified as Actinobacteria. Generally, kocurial species are harmless bacteria that can be found in human [2], sediments [3], soil [4], water, [5] and food [6] or associated with plants [7]. Significant ecological and environmental roles of Kocuria spp. have been documented in many previous studies. Cleaning up environments from hazardous aliphatic and aromatic compounds has been reported [8-9]. Furthermore, production of probiotics, bioactive and plantgrowth promoting compounds are examples of the beneficial roles of Kocuria spp. [10-13]. Nonetheless, certain members of the genus Kocuria are human pathogens such as K. kristinae [14], K. palustris [15], K. marina [16], K.rosea [17], indicating the spectrum of human infections is expanded.

\footnotetext{
* Corresponding Author

Biological Science Department, Faculty of Sciences, King Faisal

University, Saudi Arabia. E-mail: akhalifa@ kfu.edu.sa
}

Like many other bacterial diseases, antibiotics are powerful means in fighting infections caused by virulent Kocuria spp. Killing or preventing reproduction are the two strategies that antibiotics exert their actions against bacterial pathogens. Yet, emergence of antibiotic resistance has become a catastrophic crisis that threatens the outstanding benefits that gained from wise-use of antibiotics worldwide. Misuse and overuse are the two main causes that lead to curbing the effectiveness of antibiotics [18]. Resistance to antibiotic could emerge from acquiring susceptible strains to resistance genes via lateral gene transfer. Additionally, bacterial cells could exhibit tolerance to antibiotic agents because they already have intrinsic resistance genes [19]. Antibiotic categories, mechanisms of action and resistance in both Grampositive and Gam-negative bacteria have recently been reviewed [20]. The scanning electron microscope is an easy and suitable tool to study the external features of microbial cells in their natural habitats at high magnification and resolution. Many studies have been conducted on known Kocuria spp. to investigate cell shape and arrangement using light microscopy and SEM, and ultrastructure using transmission electron microscopy, [21-23]. 
It was of interest to study the morphological characteristics of the recently isolated $K$. sediminis DDK6. Therefore, the aim of the current study was to investigate the external features of strain DDK6 using SEM, and to assess its intrinsic antibiotic resistance.

\section{MATERIALS AND METHODS}

\subsection{The bacterial strain}

The DDK6 strain was previously isolated from a dieselcontaminated soil; details about isolation are previously described [9]. Briefly, 0.5 gram of soil sample was enriched with diesel oil (1 $\% \mathrm{v} / \mathrm{v})$ as a single energy and carbon source, in a $200 \mathrm{ml}$ conical flask containing $50 \mathrm{ml}$ mineral salts (MS) medium with the composition; $1 \mathrm{~g}$ (NH4) $)_{2} \mathrm{SO} 4,0.8 \mathrm{~g} \mathrm{~K}_{2} \mathrm{HPO}_{4}, 0.2 \mathrm{~g} \mathrm{KH}_{2} \mathrm{PO}_{4}, 0.2 \mathrm{~g}$ $\mathrm{MgSO}_{4} \cdot 7 \mathrm{H}_{2} \mathrm{O}, 0.1 \mathrm{~g} \mathrm{CaCl}_{2} \cdot 2 \mathrm{H} 2 \mathrm{O}$, and $5 \mathrm{mg} \mathrm{FeSO} \cdot 7 \mathrm{H}_{2} \mathrm{O}$ in $1 \mathrm{~L}$ distilled water, $\mathrm{pH} 7$ ). Flasks were incubated at $30 \mathrm{C}$ with shaking for one week. After incubation, subsequent transfer of inoculum (3\%) into a fresh MS medium was performed and single colonies were obtained upon streaking on MS plates.

\subsection{Scanning electron microscopic examination}

For scanning electron microscope examination, a single colony of DDK6 was fixed in a 2-3\% Glutaraldehyde solution for $3-4 \mathrm{~h}$ at room temperature, and then washed three times in $0.1 \mathrm{M}$ phosphate buffer for 15 min per wash. Next, the bacterial cells were dehydrated in a graded ethanol series as follows: $35 \%, 50 \%$, $70 \%, 80 \%, 95 \%$; three changes at $100 \%$ for $15 \mathrm{~min}$ each, and a final wash in acetone for $5 \mathrm{~min}$. Cells were dried in $\mathrm{CO}_{2}$, mounted on aluminum stubs, and sputter-coated with gold. Cells were examined and photographed using a scanning electron microscope (Joel) attached to a computer.

\subsection{Intrinsic antibiotic resistance of the strain DDK6}

DDK6was further tested for its susceptibility to 10 different antibiotics. Fresh bacterial culture of DDK6was spread homogenously onto nutrient agar plates. Commercially available

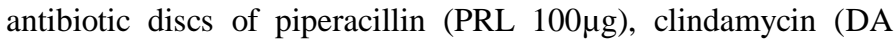

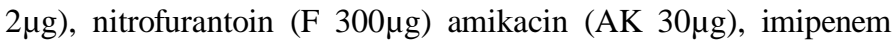

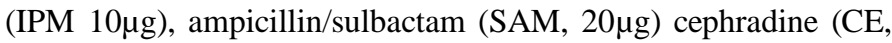
$30 \mu \mathrm{g})$, chloramphenicol $(\mathrm{C}, 30 \mu \mathrm{g})$, erthromycin $(\mathrm{E}, 15 \mu \mathrm{g})$ and tetracycline (TE, $30 \mu \mathrm{g}$ ) were carefully placed on the inoculated plates under aseptic conditions. Plates were incubated at $30^{\circ} \mathrm{C}$ for 24h. Observation of inhibition zone around the antibiotic discs highlighted that the DDK6 is sensitive to the antibiotic tested at the concentration applied. The average diameter of the zone was estimated for each antibiotic disc. The experiment was carried out in triplicate.

\section{RESULTS AND DISCUSSION}

K. sediminis strain DDK6 was isolated from dieselcontaminated soils from a petrol station in Al-Hofuf, Saudi Arabia. The cultural, biochemical and molecular characteristics were recently described [9].

\subsection{Scanning electron microscope}

Application of the scanning electron microscope is microbiology provides deep insights and understanding of many aspects of microbes such as cell shape, arrangements, cell-cell communication and division. SEM is a feasible and powerful tool for investigation of the morphological characteristics of microbial cells in their natural habitats at high magnification and resolution. Taking advantage of the SEM, DDK was investigated in the present study. Cells of the strain DDK6 appeared as typical cocci with a diameter of (0.7 - 0.9 um) and arranged in pairs (Fig.1 A and B), tetrads (Fig.1 C and D) and grapelike clusters (Fig.2 A D). These diverse arrangements were consistent with that expected to different species of Kocuria such as $K$. palustris and K. rhizophila [24], K. marina [25], K. aegyptia [26], K. sediminis FCS-11 $1^{\mathrm{T}}[3]$. The surface of the strain DDK6 (Figs 1 and 2) seemed to be relatively smooth in texture. This finding confirmed the characteristic feature of Gram-positive bacteria; they have smooth surfaces. DDK6 is a Gram-positive bacteria and not an exception. Occasionally, some cells appeared with protrusions of the surface this could be artifact occurred during fixation and dehydration processes of the sample. Another characteristic feature that was observed on the surface of the DDK6 is the appearance of ridges (arrowed in Fig. 1 B, Fig.2B), that run along the circumference of the cell. As can be seen in Figure ridges could divide the cell surface into two parts. Such ridges were observed in Gram-positive bacteria such as Bacillus subtilis and Staphylococcus haernolyticus but not in Gramnegative bacteria (Escherichia coli) [27], [28]. Such differences in surface appearance are attributed to the chemical composition of the cell walls of Gram-positive and Gram-negative bacteria. The outer membrane is a unique feature of the later. The area separated by the ridge formation is likely to be the surfaces of the old and the newly formed cells indicating a peculiar mechanism of cell wall formation during division of the DDK6. Viewing cells of strain DDK6 over a small scanning area showed that rings with two perpendicular lines in tetrads indicating division septum (Fig. 1C. The observation of the circumferential rings in different angles indicates different planes of divisions. This ring is likely to be the $\mathrm{Z}$ ring which is formed by polymerization of a highly protein called FtsZ, at the cell division site. Thus, the main function of $Z$ ring is to mark site of the cell division [29]. The existence of a diverse cell arrangement of the strain DDK6 is likely to be an advantage to best suit its lifestyle and occurrence in divers environmental niches.

Recently, it has been reported that spatial regulation of bacterial cell division is species-specific. To ensure the proper and equal partitioning of DNA into daughter cells, bacterial species adjust the position of the cell division site to cope with the mode of living and the habitat in which they live [30]. Additionally, the depth of the circumferential rings could differentiate between bacterial strains based on the antibiotic susceptibility in certain bacterial species such as Staphylococcus aureus exposed to the vancomycin [31]. Whether or not this happens to the DDK6 needs further investigation. 

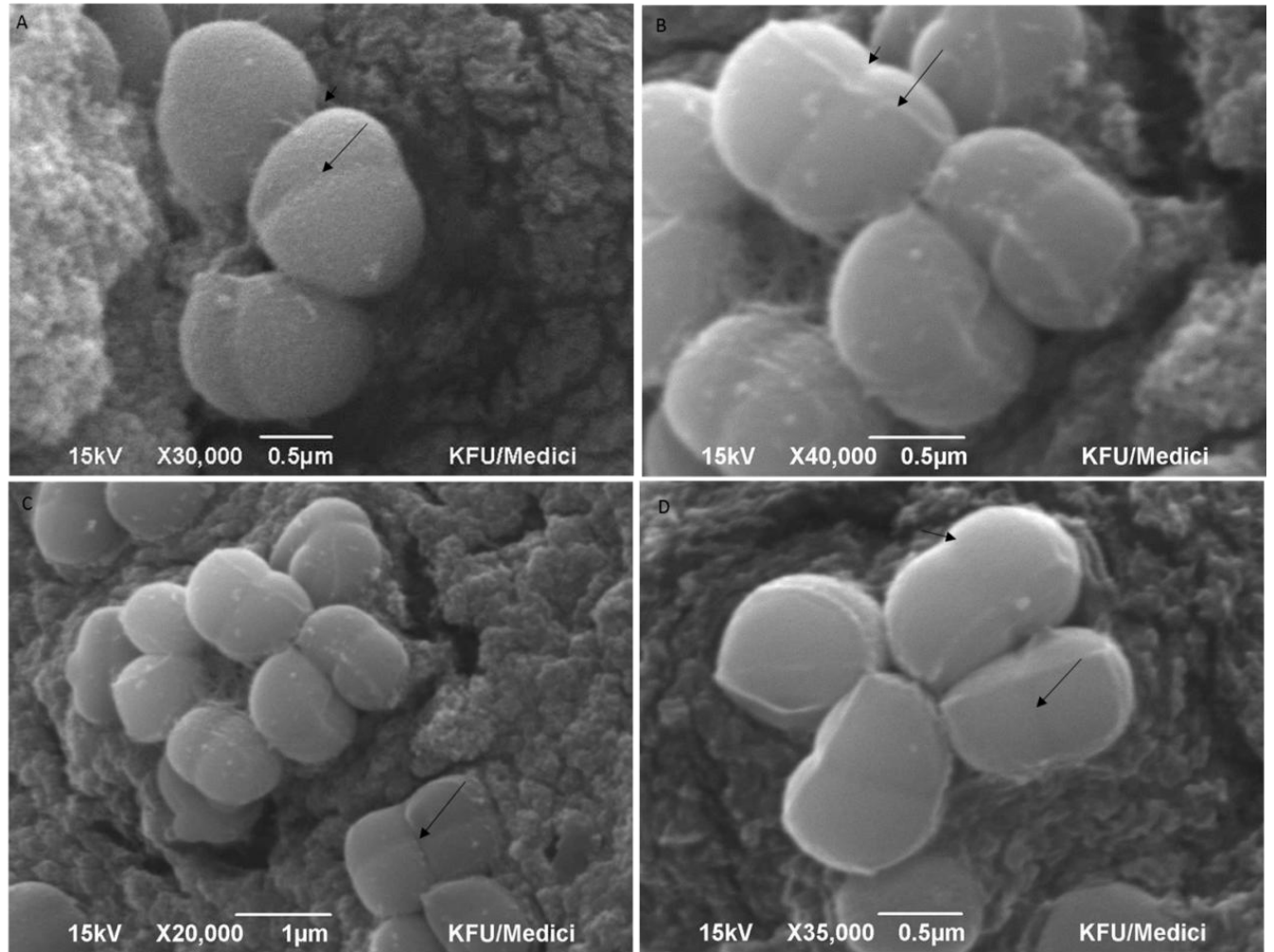

Fig. 1: Scanning electron micrographs showing the arrangements of the DDK6 cells: A, cells in pairs, dividing cells with shallow groove (long arrow) cell connections (short arrow), B, cells in pairs with deeper groove (short arrow), C, cells in tetrads and D, cells in cubes. Magnification and scale bar are written at the bottom of each image.
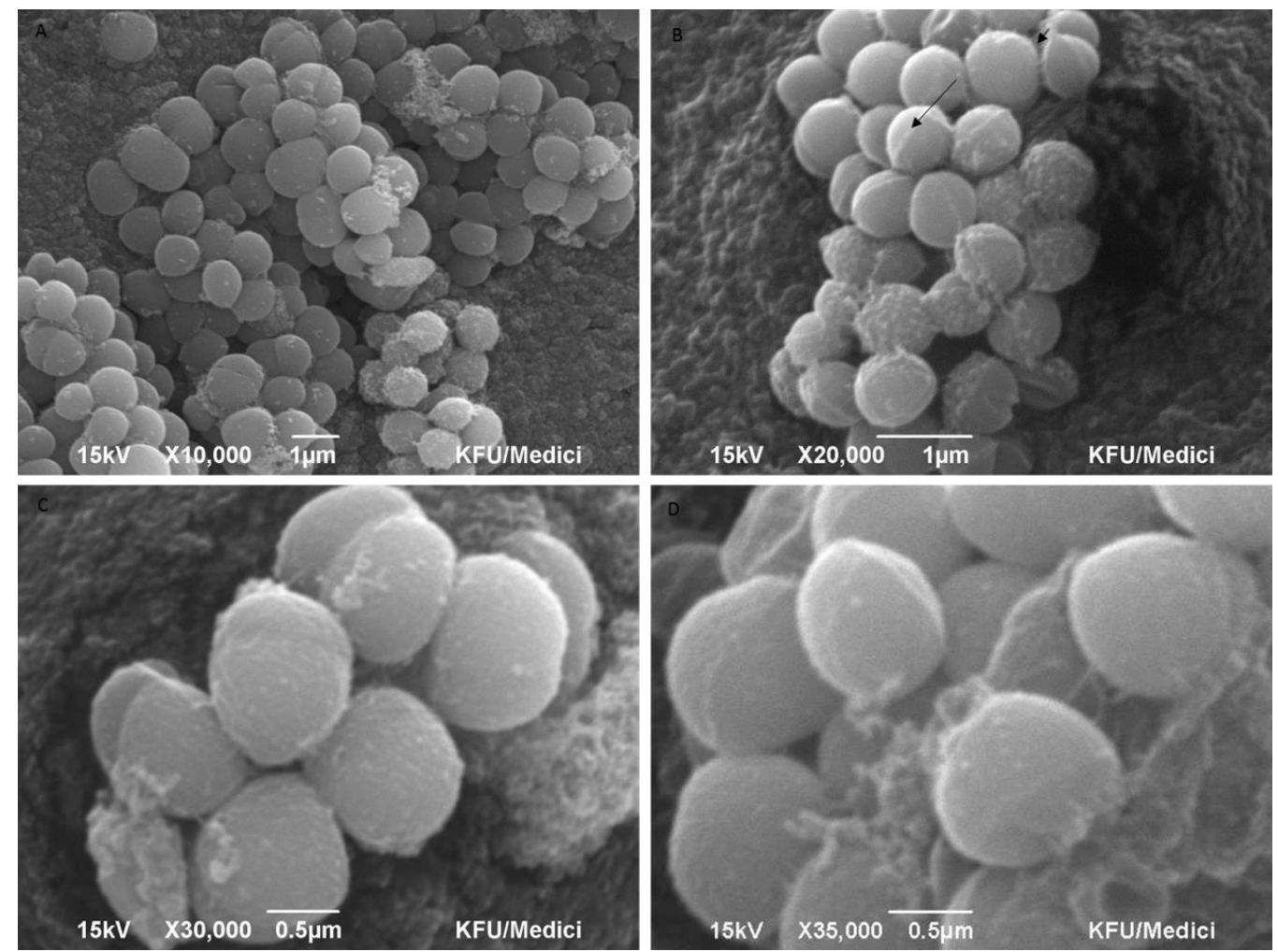

Fig. 2: Scanning electron micrographs showing the grape-like arrangements of the DDK6 cells: A, cells in clusters with relatively smooth surfaces, B, cells within circumferential ring indicating the division plane, pairs with deeper groove (short arrow), C, cells in tetrads and D, cells in cubes. Magnification and scale bar are written at the bottom of each image. 
Table 1: Intrinsic antibiotic resistance of the strain DDK6.

\begin{tabular}{|c|c|c|c|c|}
\hline Antibiotic name & Antibiotic class & Mechanism of action & $\begin{array}{c}\text { Concentration } \\
(\mu \mathrm{g})\end{array}$ & $\begin{array}{c}\text { Diameter of } \\
\text { inhibition zone } \\
(\mathrm{cm})\end{array}$ \\
\hline Ampicillin/sulbactam (SAM)* & Penicillins/Penicillin combinations & Inhibition of peptidoglycan synthesis & 20 & $0.85 \pm 0.04$ \\
\hline Cephradine $(\mathrm{CE})$ & Cephalosporin & Inhibition of peptidoglycan synthesis & 30 & $0.85 \pm 0.02$ \\
\hline Chloramphenicol (C) & Cephalosporins & Inhibition of peptidoglycan synthesis & 30 & $1.2 \pm 0.08$ \\
\hline Imipenem (IPM) & Carbapenems & Inhibition of peptidoglycan synthesis & 10 & $0.85 \pm 0.04$ \\
\hline Piperacillin (PRL) & Penicillins & Inhibition of peptidoglycan synthesis & 100 & $0.85 \pm 0.04$ \\
\hline Amikacin $(\mathrm{AK})^{*}$ & Aminoglycosides & Inhibition of protein synthesis & 30 & $0.95 \pm 0.04$ \\
\hline Clindamycin (DA) & Lincosamides & Inhibition of protein synthesis & 2 & $0.85 \pm 0.04$ \\
\hline Erthromycin (E) & Macrolides & Inhibition of protein synthesis & 15 & $1.3 \pm 0.05$ \\
\hline Tetracycline (TE) & Tetracyclines & Inhibition of protein synthesis & 30 & $1.1 \pm 0.05$ \\
\hline Nitrofurantoin $(\mathrm{F})$ & Nitrofurans & DNA damage & 300 & $\mathrm{R} * *$ \\
\hline
\end{tabular}

*: the abbreviation of the antibiotic tested.**: $\mathrm{R}$ means resistant.

\subsection{Intrinsic antibiotic resistance}

In general, DDK6 strain was sensitive to antibiotic tested at the applied concentration, except for the nitrofurantoin (F 300 $\mu \mathrm{g})$. The diameter of the inhibition zone ranged between $0.85-1.3$ $\mathrm{cm}$ highlighting variations in susceptibility levels to the antibiotic tested. The sensitivity of the strain DDK6 to the antibiotics used in the current study is accordant with those obtained by Ma et al. (2005) [31]who reported that $K$. kristinae was sensitive to clindamycin, erythromycin cloxacillin, linezolid, penicillin, trimethoprim/sulfamethoxazole, vancomycin and levofloxacin. Additionally, the majority of 219 strains belonged to Kocuria and Micrococcus exhibited sensitivity to many antibiotics such as amikacin, cefuroxime, amoxicillin but not to ampicillin and erythromycin[33]. Susceptibility of the strain DDK6 to the different antibiotics tested could be partly attributed to the lack of an outer membrane and existence of compatible antibiotic targets in this organism. However, resistance of DDK6 to the nitrofurantoin coincides with that reported to all Kocuria spp. and can be explained by the presence of efflux pumps and a decrease in the cell wall permeability [34-35]and/or lack of targets that can be attacked by the antibiotic [19]. Unlike what expected, no $\beta$ lactamase was observed by these strains [32]indicating an alternative mechanism of ampicillin resistance other than production of $\beta$ - lactamase in Gram-positive bacteria. Resistance to nitrofurantoin could be used, in addition, to many other phenotypic traits for identification of Kocuria spp.

The antibiotic mechanism of actions varied in targeting vital components in the bacterial cells (Table1). Certain antibiotics such as cephradine could inhibit cell wall synthesis via inactivation of penicillin-binding proteins and cross-linking of the peptidoglycan. Consequently, bacterial cell lysis occurred. A combination of two different antibiotics such as ampicillin/ sulbactam (SAM) has a synergistic effect in bacterial growth inhibition. In this combination, the role of sulbactam is to decrease bacterial resistance mechanisms to ampicillin. Additionally, key molecules that are involved in the protein synthesis, such as $30 \mathrm{~S}$ ribosome and $30 \mathrm{~S}$ ribosome, could be targets of aminoglycosides (e.g., amikacin) 30S ribosome Lincosamides (e.g., clindamycin), respectively [20].
Nitrofurantoin exerts its action against susceptible bacterial strain via interfering with DNA synthesis [20]. Nevertheless, resistant strains develop chromosomal or plasmidinterceded mechanisms that involves inactivation of the of the nitrofuran reductase [20], [36], preventing the subsequent damage of molecules involved in DNA synthesis. Whether or not such mechanism is mediated by the strain DDK6 to nitrofuran requires further investigations.

In conclusion, DDK6 could adjust the position of the cell division site to cope with the habitat in which it lives, and resistance to the nitrofurantoin could be used as a rapid identification of Kocuria spp, in addition, to many other phenotypic traits.

\section{ACKNOWLEDGMENTS}

Thanks to Mr. Hany Al-Rosasy and Mr. Waleed Ali for the technical assistance with scanning electron microscopy.

\section{FUNDING}

This research did not receive any specific grant from funding agencies in the public, commercial, or not-for-profit sectors.

\section{CONFLICT OF INTERESTS}

The author declares that there is no conflict of interest.

\section{REFERENCES}

1. Stackebrandt E, Koch C, Gvozdiak O, Schumann P. Taxonomic dissection of the genus Micrococcus: Kocuria gen. nov, Nesterenkonia gen. nov, Kytococcus gen. nov, Dermacoccus gen. nov, and Micrococcus Cohn 1872 gen. emend. Int. J. Syst. Bacteriol. 1995; 45: 682-692.

2. Mori, N., Nishihara, Y., Tayama, H., Higuchi, A., \& Aoki, Y. Peripherally inserted central catheter-related bloodstream infection caused by Kocuria marina in an elderly man. Infection.2017;1-4.

3. Bala M, Kaur C, Kaur I, Khan F, and Mayilraj S.. Kocuria sediminis sp. nov, isolated from a marine sediment sample. Antonie Van Leeuwenhoek.2012; 3:469-478.

4. Wang K, Zhang L, Liu Y, Pan Y, Meng L, Xu T, Zhang C, Liu H, Hong S, Huang H, and Jiang J.. Kocuria dechangensis sp. nov, an 
actinobacterium isolated from saline and alkaline soils. Int. J. Syst. Evol. Microbiol. 2015; 65: 3024-3030.

5. Seo YB, Kim DE, Kim GD, Kim HW, Nam SW, Kim YT, Lee JH. Kocuria gwangalliensis sp. nov, an actinobacterium isolated from seawater. Int. J. Syst. Evol. Microbiol.2009; 59: 2769-2772.

6. Yun JH, Roh SW, Jung MJ, Kim MS, Park EJ, Shin KS, Nam YD and Bae JW . Kocuria salsicia sp. nov, isolated from salt-fermented seafood. Int. J. Syst. Evol. Microbiol. 2011; 61: 286-289.

7. Hamada M, Shibata C, Tamura T, Nurkanto A, Ratnakomala S, Lisdiyanti P, and Suzuki KI. Kocuria pelophila sp. nov, an actinobacterium isolated from the rhizosphere of a mangrove. Int. J. Syst. Evol. Microbiol. 2016; 9: 3276-3280.

8. Esmaeil AS, Drobiova H, and Obuekwe C. Predominant culturable crude oil-degrading bacteria in the coast of Kuwait. Int. Biodeter. Biodegr. 2009; 4: 400-406.

9. Khalifa A Degradation of diesel-oil by a newly isolated Kocuria sediminis DDK6. Afr. J. Microbiol. Res. 2017. In press.

10. Sharifuzzaman SM, Al-Harbi, A H, Austin B. Characteristics of growth, digestive system functionality, and stress factors of rainbow trout fed probiotics Kocuria SM1 and Rhodococcus SM2. Aquaculture. 2014; 418: 55-61.

11. Sharifuzzaman S. M, and Austin, B. Kocuria SM1 controls vibriosis in rainbow trout (Oncorhynchus mykiss, Walbaum). J. App. microbial. 2010; 6: 2162-2170.

12. Egamberdieva D. Plant growth promoting properties of rhizobacteria isolated from wheat and pea grown in loamy sand soil. Turk. J. Biol. 2008; 1: 9-15.

13. Palomo S, González I, de la Cruz M, Martín J, Tormo JR, Anderson M, Hill R, Vicente F, Reyes F, Genilloud O. SpongeDerived Kocuria and Micrococcus spp. as sources of the new thiazolyl peptide antibiotic Kocurin. Mar. Drugs. 2013; 4: 10711086.

14. Chen, H. M., Chi, H., Chiu, N. C., \& Huang, F.Y. Kocuria kristinae: a true pathogen in pediatric patients. J Microbiol Immunol. 2015; 48(1), 80-84

15. Chander, A. M., Nair, R. G., Kaur, G., Kochhar, R., Mayilraj, S., Dhawan, D. K., \& Bhadada, S. K. Genome sequence of Kocuria palustris strain CD07_3 isolated from the duodenal mucosa of a celiac disease patient. GenomeA, 2016; 4(2), e00210-16.

16. Loong, S. K., Johari, J., Che Mat Seri, N. A. A., AbdulRazak, O., Douadi, B., Ahmad Nasrah, S. N., ... \& AbuBakar, S. Research Note Isolation and Identification of an Emerging Pathogen, Kocuria marina, from Rattus rattus diardii. Trop. Biomed. 2016; 33(3), 589593.

17. AlWakeel, S. S. Microbiological and molecular identification of bacterial species isolated from nasal and oropharyngeal mucosa of fuel workers in Riyadh, Saudi Arabia. Saudi J. Biol. Sci . 2015, Dec. 1, http://dx.doi.org/10.1016/j.sjbs.

18. Ventola CL. The Antibiotic Resistance Crisis: Part 1: Causes and Threats.Pharm. Ther. 2015; 40(4), 277-283.

19. Gang, Z., \& Jie, F.. The intrinsic resistance of bacteria. Yi chuan= Hereditas, 2016; 38(10), 872.

20. Perry, C., \& Hall, C. Antibiotic resistance: how it arises, the current position and future strategies. Benefits, 2017; 10, 32.

21. Tang, S. K., Wang, Y., Lou, K., Mao, P. H., Xu, L. H., Jiang, C. L., \& Li, W. J. Kocuria halotolerans sp. nov., an actinobacterium isolated from a saline soil in China. Int. J. Syst. Evol. Microbiol. 2009; 59(6), 1316-1320.

22. Jiang, Z., Zhang, W. H., Yuan, C. G., Chen, J. Y., Cao, L. X., Park, D. J., \& Li, W. J. Kocuria subflava sp. nov., isolated from marine sediment from the Indian Ocean. Antonie van Leeuwenhoek, 2015; 108(6), 1349-1355.
23. Román-Ponce, B., Wang, D., Vásquez-Murrieta, M. S., Chen, W. F., Estrada-de los Santos, P., Sui, X. H., \& Wang, E. T. Kocuria arsenatis sp. nov., an arsenic-resistant endophytic actinobacterium associated with Prosopis laegivata grown on high-arsenic-polluted mine tailing. Int. J. Syst. Evol. Microbiol.2016; 66(2), 1027-1033.

24. Kovács G, Burghardt J, Pradella S, Schumann P, Stackebrandt E. and Màrialigeti K. Kocuria palustris sp. nov. and Kocuria rhizophila sp. nov, isolated from rhizoplane of the narrow-leaved cattail (Typha angustifolia). Int. J. Syst. Bacteriol. 1999; 49: 167-173.

25. Kim, S. B., Nedashkovskaya, O. I., Mikhailov, V. V., Han, S. K., Kim, K. O., Rhee, M. S. \& Bae, K. S. Kocuria marina sp. nov., a novel actinobacterium isolated from marine sediment. Int. J. Syst. Evol. Microbiol.2004;54, 1617-1620.

26. Li, W. J., Zhang, Y. Q., Schumann, P., Chen, H. H., Hozzein, W. N., Tian, X. P., Xu, L. H. \& Jiang, C. L. Kocuria aegyptia sp. nov., a novel actinobacterium isolated from a saline, alkaline desert soil in Egypt. Int. J. Syst. Evol. Microbiol.2006; 56, 733-737

27. Amako, K., \& Umeda, A. Bacterial surfaces as revealed by the high resolution scanning electron microscope. Microbiology, 1977; 98(1), 297-299.

28. Umeda, A., Saito, M., \& Amako, K.. Surface characteristics of Gram-negative and Gram-positive bacteria in an atomic force microscope image. Microbiol. Immunol. 1998; 42(3), 159-164.

29. De Boer, P. A. Advances in understanding E. coli cell fission. Curr Opin. Microbiol. 2010; 13(6): 730-737.

30. Monahan LG, Liew ATF, Bottomley AL, Harry EJ.Division site positioning in bacteria: one size does not fit all. Front. Microbiol.2014; 5:19. doi:10.3389/fmicb.2014.00019.

31. Boyle-Vavra S, Hahm J, Sibener SJ, Daum RS.Structural and Topological Differences between a Glycopeptide-Intermediate Clinical Strain and Glycopeptide-Susceptible Strains of Staphylococcus aureus Revealed by Atomic Force Microscopy. Antimicrob. Agents. Ch.2000; 44(12):3456-3460.

32. Ma ES, Wong CL, Lai KT, Chan EC, Yam W, Chan AC. Kocuria kristinae infection associated with acute cholecystitis. BMC Infectious Diseases.2005,5:60. doi:10.1186/1471-2334-5-60.

33. Szczerba I. Susceptibility to antibiotics of bacteria from genera Micrococcus, Kocuria, Nesternkonia, Kytococcus and Dermacoccus. Med Dosw Mikrobiol. 2003; 55:75-80.

34. Savini, V., Catavitello, C., Masciarelli, G., Astolfi, D., Balbinot, A., Bianco, A., D'antonio, D.Drug sensitivity and clinical impact of members of the genus Kocuria. J. Med. Microbial.2010; 59(12), 1395-1402.

35. Purty, Shashikala et al. The Expanding Spectrum of Human Infections Caused by Kocuria Species: A Case Report and Literature Review. Emerging Microbes \& Infections . 2013;2(10): e71-. PMC. Web. 24 Feb. 2017.

36. McCalla DR, Kaiser C, Green MH. Genetics of nitrofurazone resistance in Escherichia coli. J. Bacteriol. 1978; 133: 10-16.

\section{How to cite this article:}

Ashraf Y. Z. Khalifa. Scanning electron microscopy and antibiotic sensitivity of the actinobacterium, Kocuria sediminis DDK6. J App Biol Biotech. 2017; 5 (03): 018-022. 